This item was submitted to Loughborough's Research Repository by the author.

Items in Figshare are protected by copyright, with all rights reserved, unless otherwise indicated.

\title{
Adhesion of precision welded lead-free electrical interconnects formed by molten droplet deposition
}

\section{PLEASE CITE THE PUBLISHED VERSION}

\section{PUBLISHER}

Professional Engineering Publishing (@ IMechE)

VERSION

VoR (Version of Record)

\section{LICENCE}

CC BY-NC-ND 4.0

\section{REPOSITORY RECORD}

Webb, D. Patrick, Changqing Liu, Farhad Sarvar, Paul P. Conway, and K. Williams. 2019. "Adhesion of Precision Welded Lead-free Electrical Interconnects Formed by Molten Droplet Deposition”. figshare. https://hdl.handle.net/2134/4682. 
This item was submitted to Loughborough's Institutional Repository (https://dspace.lboro.ac.uk/) by the author and is made available under the following Creative Commons Licence conditions.

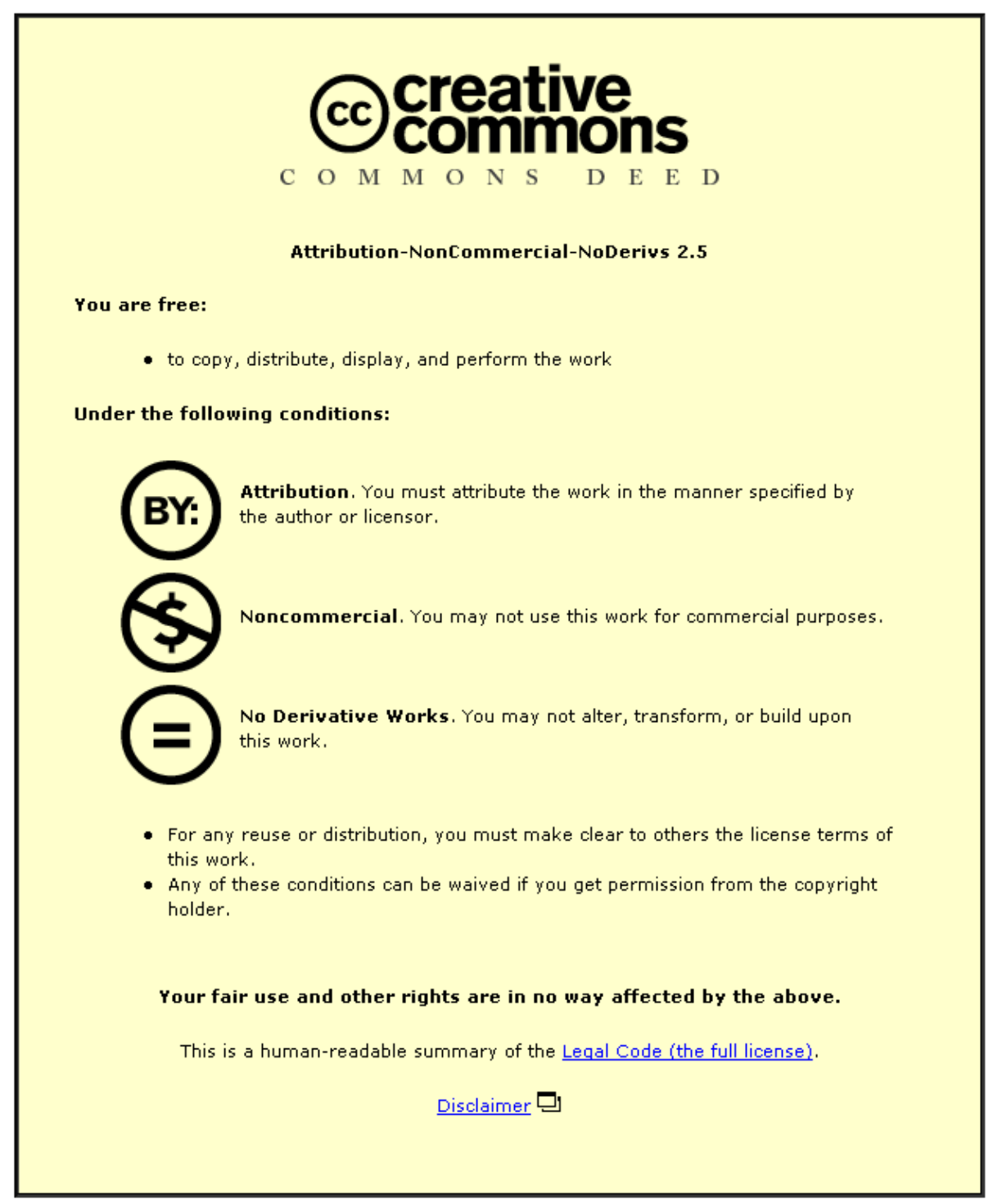

For the full text of this licence, please go to: http://creativecommons.org/licenses/by-nc-nd/2.5/ 


\title{
Adhesion of precision welded lead-free electrical interconnects formed by molten droplet deposition
}

\author{
D P Webb*, C Liu, F Sarvar, P P Conway, and K Williams \\ School of Mechanical and Manufacturing Engineering, Loughborough University, Loughborough, UK
}

The manuscript was received on 18 April 2005 and was accepted after revision for publication on 25 October 2006.

DOI: 10.1243/09544054JEM365

\begin{abstract}
An existing process, droplet welding, has been proposed for the production of precision, high-temperature, lead-free electrical joints. A modified metal inert gas (MIG) welding plasma is used to produce molten metal droplets, which then fall on a part to make an electrical joint. The subject of the present paper is an investigation of the factors affecting successful welded joint formation for a given droplet material and target, with the goal of providing the basis of a computer model to enable rapid process set-up on a production line. It is found that a parameter space can be identified for good adhesion of a droplet to a target, characterized by droplet temperature and target thickness, for each droplet material/target material combination. Essentially adhesion can be viewed as determined by competition between the delivery of thermal energy from the droplet to the target immediately underneath the droplet, and the removal of the energy from the interface region to the rest of the target, with no role played by the droplet kinetics after impact. It is therefore concluded that a relatively simple thermal model could be used by production-line engineers to identify the parameter space for rapid process set-up with new material combinations and products. The conclusion is supported by evidence from high-speed video images of droplet impact. Such a simple thermal model is proposed and is found to be capable of predicting adhesion between droplet and target. The results are discussed in the context of the extensive literature on molten droplet impact and solidification.
\end{abstract}

Keywords: lead-free, high temperature electrical joint, joint formation, molten droplet impact, precision joining, joint adhesion

\section{INTRODUCTION}

The EC Directive on the restriction of the use of certain hazardous substances in electrical and electronic equipment (RoHS)[1] bans the use of lead in the manufacture of most electrical and electronic equipment in the European Union from July 2006. Electrical components, fine mechanical devices, and the electrical equipment industry require low cost replacements for lead solders. Lamp manufacture alone produces $200 \mathrm{t}$ per annum of lead waste in Europe [2]. In particular, high-temperature, cost-effective replacements are not readily available.

Droplet welding represents a solution that utilizes low-cost lead-free alternatives. It is based

*Corresponding author: Mechanical and Manufacturing Engineering, Loughborough University, Loughborough, Leicestershire LE11 3TU, UK. email: D.P.Webb@lboro.ac.uk on a modified metal inert gas (MIG) welding process and is currently used in lamp/light bulb manufacture with tin-lead alloys. The welding material is fed as a wire through the welding head, is melted and ejected as a droplet on the target, forming a weld and making an electrical connection. The existing process produces droplets of diameter around $1 \mathrm{~mm}$ at a rate of some 10 per second. A variety of other welding materials can be used, such as copper, aluminium, chromium, nickel, and aluminium-silicon alloys.

To extend the process for wider use in the electronics industry, a number of issues need to be addressed. These include reducing the droplet size, reducing droplet variation, improving droplet deposition lateral accuracy, accounting for the fit of parts to be joined, and minimizing the thermal effects on products of droplets and plasma exhaust gases. The subject of the current paper is 
an investigation of the factors affecting successful welded joint formation for a given droplet material and target. Droplet adhesion for a matrix of droplet materials, target materials, target thicknesses, and welding currents was assessed. The factors determining adhesion were then investigated by thermal modelling and high-speed imaging of droplet impacts. A particular question addressed was what is the degree of influence of the kinetic and heat energy of an impacting droplet on the quality of the joint formed.

The work formed part of a wider project on the arc-plasma droplet welding process and an alternative laser-based droplet process. The main aim was to enable rapid process set-up of the machine for manufacture of new products, rather than in-depth study of the physics of joint formation. However, in addition to addressing the industrial imperatives the study does make a contribution to the literature on the much-studied topic of molten droplet impact on solid surfaces, by considering the issues of joint adhesion and finite target thickness.

\section{BACKGROUND}

Study of molten droplet impact and solidification on solid surfaces was driven initially by interest in the technique of thermal spray coating, used to form a protective coating on a target by spraying with molten droplets that subsequently freeze in place. More recently spray forming methods have been used for manufacturing by controlled deposition of molten droplets to build up a part in layers, while solder jetting [3] has been investigated for the deposition of solder on micro-electronic component bond pads.

Interest has concentrated on prediction of the shape of a droplet after impact and freezing. This depends on factors such as the impact velocity, temperatures of the droplet and target, and thermal parameters of the droplet and target materials. The physical behaviour is complex because the droplet deforms and solidifies simultaneously, while heat transfer is both conductive and convective owing to fluid flow within the droplet. For sufficiently high temperatures there is re-melting of the target at the interface with the droplet, which is presumed to be required for the formation of a good joint.

Theoretical treatments of the problem must deal with both the heat and fluid flows. One of the earliest models is that by Madejski [4] who approximated the droplet after impact as a spreading cylinder or disk. The fluid flow is treated by assuming a flow field, while the thermal flow is treated by assuming the dynamics of the vertical motion of the solidification front, from the Neumann solution to the analogous one-dimensional Stefan problem for motion of the solidification phase change boundary in a static medium; see for example Carslaw and Jaeger [5]. The motion of disk spreading is governed by the mechanical energy balance between the kinetic energy owing to the impact velocity of the droplet, and the potential energy caused by the liquid surface tension, with dissipation attributed to fluid viscous forces.

Refinements to Madejski's approach have included consideration of partial solidification of a droplet before impact [6], and improvement to the assumed fluid flow field [7]. These papers relate to the case of droplets travelling at high velocity that spread on impact into a thin 'splat' and freeze, with the aim being to predict the diameter of the splat. Kim and Chun [8] and Yang et al. [9] also used a cylinder approximation to cover the case where droplets experience recoil, i.e. remain liquid long enough to contract after expansion. Rangel and Bian [10] did not assume the kinetics of the propagation of the solidification front in their analysis, but obtained it by coupling separate solutions for the thermal energy equation in the liquid and solid domains. They were thus able to examine the effects of substrate re-melting.

Simplified models have the advantage of providing physical insight and producing equations that require relatively little computational effort to solve. This makes them suitable for process optimization against parameters such as final droplet diameter. More complex models solve the Navier-Stokes and heat-energy governing equations on a spatial mesh [11-14]. These can provide insight into the solidification process by providing details of the transient temperature distributions and fluid flows within the droplet and substrate that are not accessible experimentally. Comparisons of details of the shape of the solidified droplet with experiment help to validate the models. Spatially resolved models also allow cases such as rough [15] and angled [16] target surfaces to be examined.

\section{EXPERIMENTAL DETAILS}

The study was conducted using a droplet welding machine designed for welding of high-temperature lamp filaments. The apparatus comprised the welding head, a variable wire feed, a power supply, and an XY movable sample stage. The welding head of the droplet welding machine is illustrated in Fig. 1. A nozzle surrounds a contact tube through which a continuous wire electrode can be fed. An argon shield gas flows between the nozzle and contact tube. Three tungsten cathodes are arranged in a ring symmetrically about the point where the 


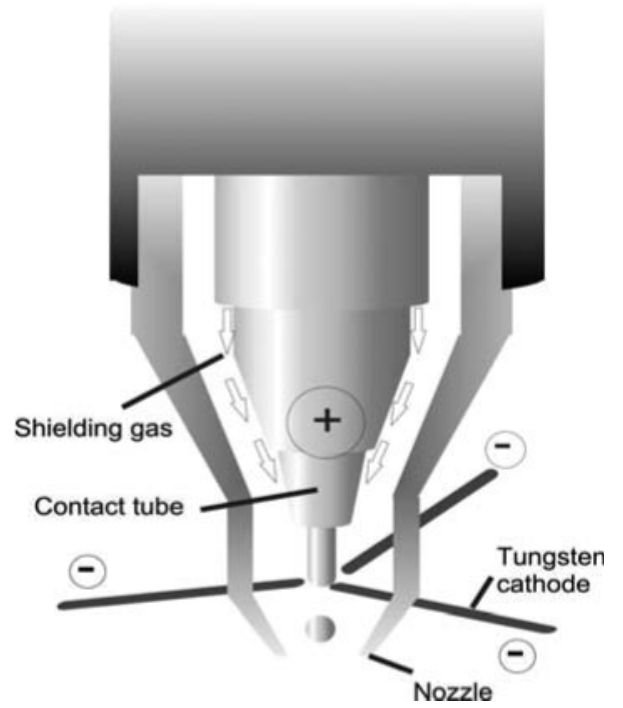

Fig. 1 Schematic of the interior of the welding head used to produce the molten droplets

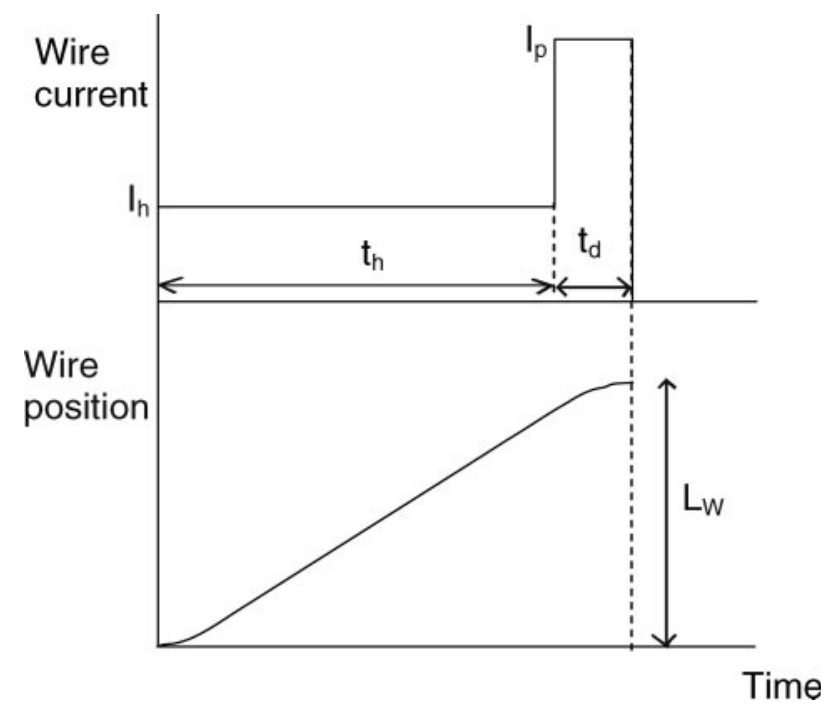

Fig. 2 Relationship between droplet-generation current and wire movement during droplet generation

wire emerges from the contact tube. To enable highspeed operation on the production line the apparatus is maintained in a ready state by a background, continuous arc plasma created in the argon shield gas by a current between the three tungsten cathodes and the contact tube as anode. A pendant molten droplet is formed on the end of the wire and then ejected as the wire is fed through the torch head while simultaneously a transient current pulse is passed through the cathodes with the wire as anode.

The time evolution of the current pulse and the wire movement is illustrated in Fig. 2. A chosen length of wire $L_{\mathrm{w}}$ is fed through the torch head at a programmed acceleration and maximum velocity. The simultaneous current pulse consists of a heating pulse of current $I_{\mathrm{h}}$ and duration $t_{\mathrm{h}}$, followed by a relatively short high current 'pinch' pulse, of current and duration $I_{\mathrm{p}}$ and $t_{\mathrm{p}}$. During the heating pulse a pendant molten droplet is formed at the end of the moving wire. The pinch pulse serves to complete the growth of the pendant droplet and then detach the droplet.

The wire delivery and current pulse parameters used in the experiments were as follows. The wire feed acceleration and maximum velocity were $14.0 \mathrm{~m} / \mathrm{s}^{2}$ and $6.80 \times 10^{-2} \mathrm{~m} / \mathrm{s}$ respectively, producing a wire feed length of $2.8 \mathrm{~mm}$. The wire movement start time, acceleration, and velocity parameters were chosen so that the wire movement ended around $1 \mathrm{~ms}$ before the end of the pinch pulse. Copper and nickel wire both of diameter $1 \mathrm{~mm}$ were used. For copper the pulse parameters were $t_{\mathrm{h}} 40 \mathrm{~ms}, I_{\mathrm{p}} 225 \mathrm{~A}$, and $t_{\mathrm{p}} 4.5 \mathrm{~ms}$, and for nickel $t_{\mathrm{h}} 37.5 \mathrm{~ms}, I_{\mathrm{p}} 240 \mathrm{~A}$, and $t_{\mathrm{p}} 10.0 \mathrm{~ms}$. The heating current magnitude $I_{\mathrm{h}}$ was varied between $50 \mathrm{~A}$ and 83.1A during the adhesion tests as described in the results section. The droplet mass was determined for the copper wire to be the same as the wire feed mass to within \pm 0.5 per cent for the copper pulse parameters above and $I_{\mathrm{h}}$ values of $50 \mathrm{~A}, 60 \mathrm{~A}, 70 \mathrm{~A}$, and $80 \mathrm{~A}$. The droplet mass was measured for each current value as follows. Ten droplets were produced in rapid succession and caught in a pre-weighed container. The container with droplets was then weighed. The wire feed mass was equivalent to a volume of $2.2 \mathrm{~mm}^{3}$, or a sphere diameter of $1.6 \mathrm{~mm}$.

Temperatures for copper droplets quoted in this work have been calculated from the MIG current pulse parameters. The calculation is based on a previous study using the same model of droplet welding machine in which the average thermal energy per droplet $E_{\mathrm{d}}$ produced for different current pulses was measured using a calorimeter [17]. It was found that $E_{\mathrm{d}}$ was proportional to the amount of charge $Q$ passed in the MIG current pulse, such that

$$
E_{\mathrm{d}}=V_{\mathrm{w}} Q
$$

where

$$
Q=I_{\mathrm{h}} t_{\mathrm{h}}+I_{\mathrm{p}} t_{\mathrm{p}}
$$

and $V_{\mathrm{w}}$ is a proportionality constant between $Q$ and $E_{\mathrm{d}}$ with dimensions of voltage. Figure 3 is a plot of their data for $\mathrm{Cu}-2$ per cent $\mathrm{Ag}$ wire, with $E_{\mathrm{d}}$ on the $y$-axis and the ratio of current pulse charge to droplet mass $\left(Q / M_{\mathrm{dr}}\right)$ on the $x$-axis. The line represents the least squares fit value of $V_{\mathrm{w}}$ of $6.6 \mathrm{~V}$ $\pm 0.3 \mathrm{~V}$. Since roughly the same range of $\left(Q / M_{\mathrm{dr}}\right)$ has been covered in this work $(0.15 \mathrm{As} / \mathrm{kg}$ to $0.21 \mathrm{As} / \mathrm{kg})$, it was considered reasonable to use the calibration curve to calculate heat energy transferred to the copper droplets in this work.

Included in Fig. 3 are the data from other researchers using different materials: Kiyohara et al. [18], 


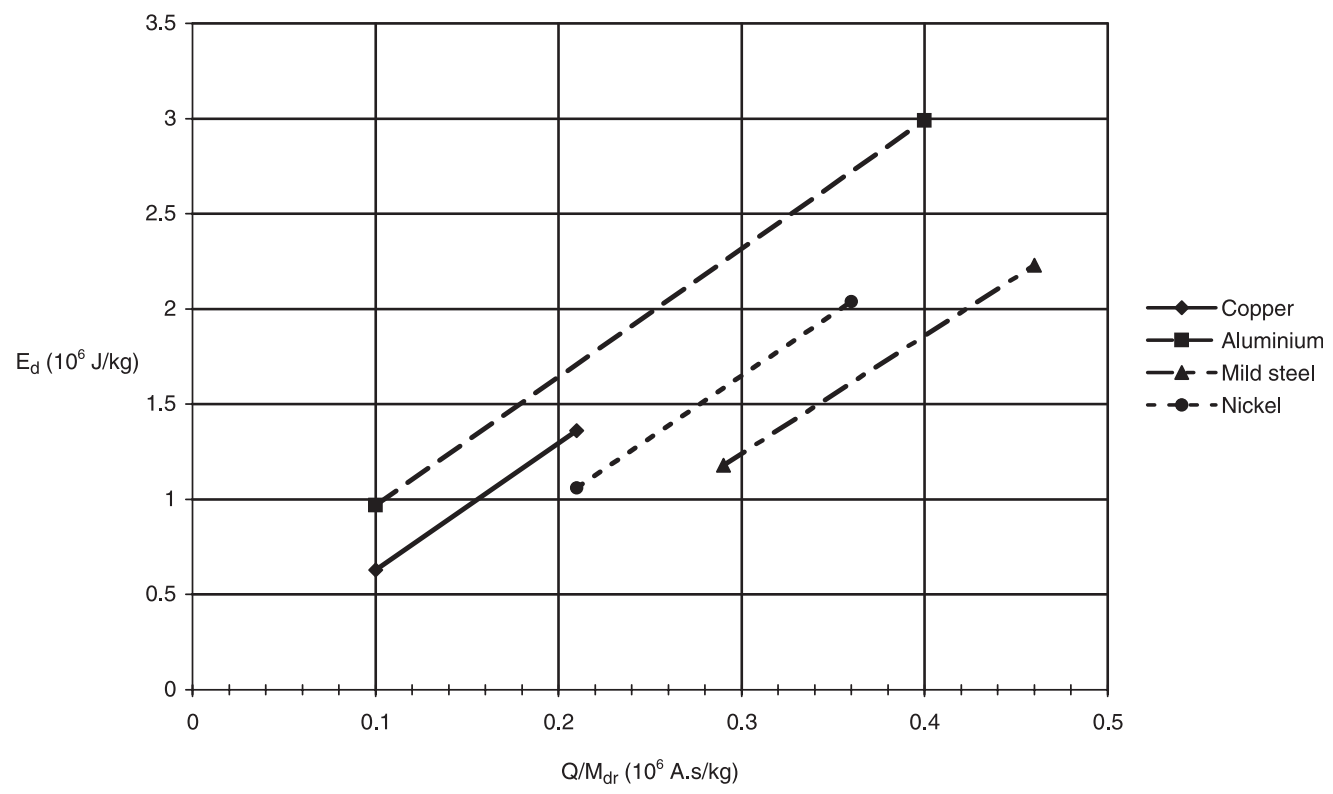

Fig. 3 Plot of energy in the weld droplet contributing to the droplet heating $\left(E_{\mathrm{d}}\right)$ against charge per unit mass of the droplet $\left(Q / M_{\mathrm{dr}}\right)$ for copper [17], aluminium [18], mild steel [19] and deduced for nickel used in this study. Minimum and maximum points plotted refer to $E_{\mathrm{d} \text { minimum }}$ to produce a molten droplet and $E_{\mathrm{d}}$ maximum to produce boiling (includes latent heat of fusion)

Table 1 Material parameters of the target plates and droplet wires [20]. 'Specific energy' values refer to the required heat energy per unit mass starting from room temperature

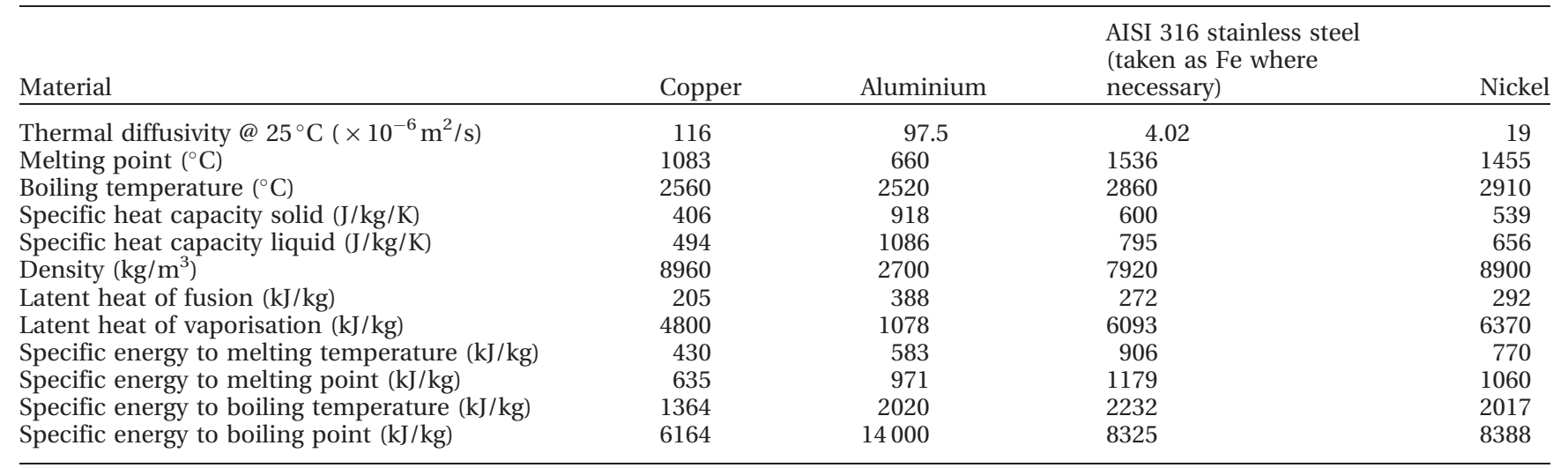

using aluminium found $V_{\mathrm{w}}=6.8 \mathrm{~V} \pm 0.5 \mathrm{~V}$ and Waszink and Van Den Heuval [19], using mild steel found $V_{\mathrm{w}}=6.0 \mathrm{~V} \pm 0.5 \mathrm{~V}$. Note the excellent agreement in the value of $V_{\mathrm{w}}$ for each of three very different materials. The minimum and maximum values of $E_{\mathrm{d}}$ for each material represent the energy required to heat unit mass of material from room temperature to melting and to boiling respectively, including the latent heat contributions as listed in Table 1.

To obtain the calibration curve for the nickel droplets, the energy per unit mass $\left(E_{\mathrm{d}}\right)$ to bring the nickel up to melting temperature and that required to bring the nickel to boiling point were calculated. The minimum ratio of current pulse charge to droplet mass $\left(Q / M_{\mathrm{dr}}\right)$ was determined experimentally from the lowest value of $Q$ at which the droplets could be produced from the nickel wire, but unfortunately the machine current limit did not allow the maximum value of $Q / M_{\mathrm{dr}}$ to be determined experimentally. Instead, this was inferred from the close agreement in the $E_{\mathrm{d}}$ versus $Q / M_{\mathrm{dr}}$ graph gradient $\left(V_{\mathrm{w}}\right)$ for very different materials (copper, aluminium, mild steel). Using the common value of $V_{\mathrm{w}}$ allowed the droplet temperature to be calculated. The error in $V_{\mathrm{w}}$ quoted above translates to an error in temperature estimated using the calibration curves of around \pm 5 per cent (for expression in ${ }^{\circ} \mathrm{C}$ ).

A movable stage to hold the target was positioned vertically underneath the welding head at a distance of $13.5 \mathrm{~mm}$ from the underside. The targets were 


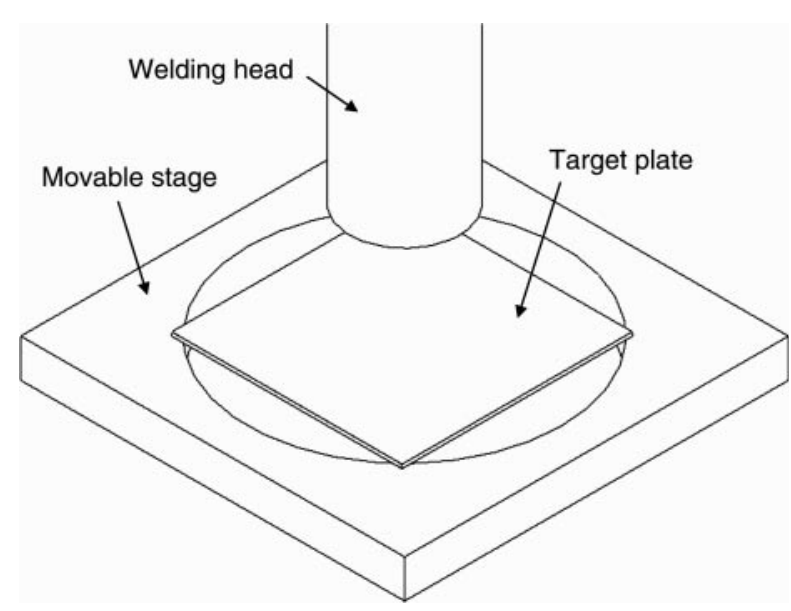

Fig. 4 Movable stage and target plate

$100 \mathrm{~mm} \times 100 \mathrm{~mm}$ square plates positioned over a $100 \mathrm{~mm}$ diameter hole in the stage, so that the majority of the underside of a target plate was exposed to air, as illustrated in Fig. 4. The plates were composed of copper, aluminium, and AISI316 stainless steel. Three different thicknesses of each material of $0.1 \mathrm{~mm}, 0.25 \mathrm{~mm}$, and $0.5 \mathrm{~mm}$ were used.

Targets placed on the stage heat up because of the background continuous arc plasma hot gas emission from the nozzle. To minimize any variation in the experimental results resulting from variations in the temperature of the targets, the length of time a target takes to reach an equilibrium temperature after being placed on the stage was investigated. The temperature rise for the $0.1 \mathrm{~mm}$ and $0.5 \mathrm{~mm}$ thickness copper plates was measured using thermocouples. Two minutes was found to be sufficient to allow the targets to complete 90 per cent of the temperature rise from ambient to the steady state temperature of around $200-300^{\circ} \mathrm{C}$. The experimental procedure for deposition of droplets for the adhesion tests was therefore as follows: the target was placed on the movable stage and allowed to heat in the hot gas emission from the nozzle of the welding head for 2 min; ten droplets were then deposited on the target at a rate of around $0.5 \mathrm{~Hz}$, fired manually, with the stage moved a few millimetres between each deposition; the target was then removed and allowed to cool. The adhesion of the droplets to the target was then evaluated through manual application of stress using tweezers. As the intended application is for non load-bearing electrical joints, this method of adhesion testing was considered sufficient.

Evaluation of the dynamics of droplet impact were studied by capturing images using an Ektapro model 4540 high-speed video camera. The images of droplet impacts were obtained at a frame rate of 4500/s. Metallographic-cross sections were prepared using an alcoholic $\mathrm{FeCl}$ etch to reveal details of the microstructure.

\section{SIMPLE THERMAL MODEL}

In order to investigate the adhesion of the molten droplet, a simple thermal model was used to describe the heat energy conducted into the top surface of the workpiece, where the droplet/workpiece interface is situated $(z=0)$. This was based on the solution to the heat conduction problem for heat supplied at a constant rate $q$ per unit time per unit area for time $t>0$ over a circle of radius $a$ at depth $z=0$ on a semi-infinite substrate [5].

$$
\begin{aligned}
\Delta T= & \frac{a q}{2 k} \int_{0}^{\infty} \mathrm{J}_{0}(\lambda r) J_{1}(\lambda a)\left\{e^{-\lambda r} \operatorname{erfc}\left[\frac{z}{2(\alpha t)^{1 / 2}}-\lambda(\alpha t)^{1 / 2}\right]\right. \\
& \left.-\mathrm{e}^{\lambda r} \operatorname{erfc}\left[\frac{z}{2(\alpha t)^{1 / 2}}+\lambda(\alpha t)^{1 / 2}\right]\right\} \frac{d \lambda}{\lambda}
\end{aligned}
$$

where $\Delta T$ is the temperature increase; $q$ is the heat flux (power per unit area); $\mathrm{J}_{0}$ is a Bessel function of the first kind, zeroth order; $J_{1}$ is a Bessel function of the first kind, first order; $r$ is the radial distance in the $x y$ plane to the origin $(0,0)$; erfc is the complementary error function; $z$ is the depth below the workpiece surface; $\alpha$ is the thermal diffusivity of the workpiece; $k$ is the thermal conductivity of the workpiece; and $\lambda$ is an integration variable. The energy conducted into the workpiece is equal to $\Delta T$ divided by the specific heat capacity of the material of the workpiece. To predict adhesion this may then be compared with the energy per unit mass required to raise the workpiece to melting temperature from room temperature (referred to in what follows as the 'melting temperature specific energy') and the energy per unit mass required to melt the workpiece including latent heat starting from room temperature (referred to in what follows as the 'melting point specific energy'). No account was made for heat loss by convection or radiation.

In order to estimate a value for the thermal input to the workpiece from the droplet $(q)$, the heat flux was considered to be the energy of the droplet released at a constant rate over the time to solidification, which in turn was estimated from the high-speed video images $(20 \mathrm{~ms})$. This will give an overestimate of the overall heat input over the $20 \mathrm{~ms}$ period, but will be lower than the initial heat flux. The heat energy contained within the droplet for different droplet materials and arc currents $\left(I_{\mathrm{h}}\right)$ was determined from Fig. 3. The droplet volume was taken from the experimental results to be $2.2 \times 10^{-9} \mathrm{~m}^{3}$ while the droplet radius once spread on the workpiece was taken to be $1.01 \mathrm{~mm}$, which represents an average of the experimentally measured diameters (see Fig. 5). Other required material parameters for the model calculations are listed in Table 1.

To determine the effect of a finite thickness workpiece, a technique called the 'method of images' was 


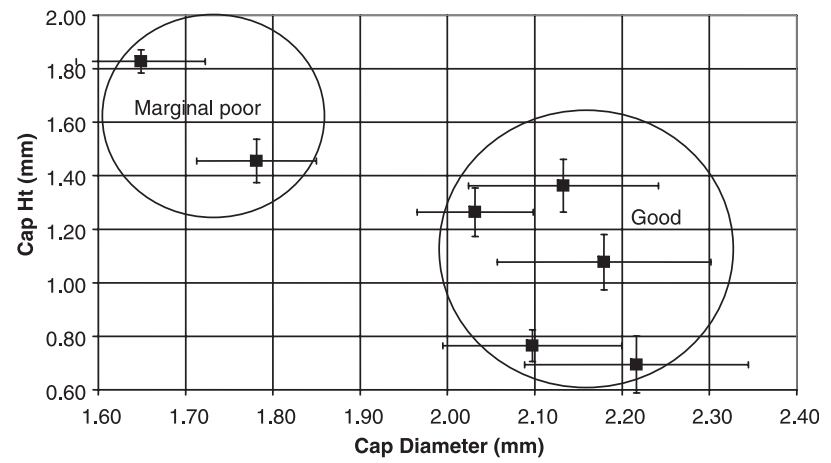

Fig. 5 Cap height versus cap diameter of adhering copper droplets from the tests summarised in Table 2. Each data point represents a different target and current pulse parameter combination. Good $=$ good adhesion. Marginal poor $=$ marginal poor adhesion

used [5]. The base and surface of the workpiece was considered a reflective surface for heat conduction, therefore the temperature at depth $z$ in a workpiece of thickness $d$ could be considered as the sum of the semi-infinite temperature prediction at depths corresponding to reflection path lengths. For the surface temperature $(z=0)$ in a sheet of thickness $d$

$$
\begin{aligned}
T(0)_{\text {finite }} \text { thickness }= & T(0)_{\text {semi-infinite }} \\
& +T(2 d)_{\text {semi-infinite }} \\
& +T(4 d)_{\text {semi-infinite }}
\end{aligned}
$$

Evaluating the equation generally requires numerical integration. The presence of the Bessel functions means that a method that will cope with oscillatory functions should be used. Most software programming packages will have subroutine libraries that can be readily used, including those to undertake transformations to cope with the Bessel functions. Mathematica software, from Wolfram, was used in this instance.

\section{RESULTS}

\subsection{Adhesion tests}

The target plates with deposited droplets were found to fall into two qualitatively distinct categories: good adhesion, where no droplets on a given plate could be removed, and poor adhesion, where all or some of the droplets fell off or could be removed easily. The results of the adhesion tests are presented in Table 2. Actual parameter combinations investigated are indicated by ' $\mathrm{Y}$ ' for good adhesion, ' $\mathrm{N}$ ' for poor adhesion, and ' $\mathrm{Y} / \mathrm{N}$ ' for marginal poor adhesion where some of the droplets on a given plate could not be removed easily. The general trend for both copper and nickel droplets is for adhesion to be
Table 2 Results of adhesion tests; $\mathrm{Y}=$ good adhesion, $\mathrm{N}=$ poor adhesion, $\mathrm{Y} / \mathrm{N}=$ marginal poor

\begin{tabular}{|c|c|c|c|c|c|c|c|c|c|}
\hline $\begin{array}{l}\text { Target } \\
\text { material }\end{array}$ & \multicolumn{3}{|c|}{$\mathrm{Cu}$} & \multicolumn{3}{|c|}{$\mathrm{Al}$} & \multicolumn{3}{|c|}{$\begin{array}{c}\text { Stainless } \\
\text { steel AISI316 }\end{array}$} \\
\hline $\begin{array}{l}\text { Thickness } \\
(\mathrm{mm})\end{array}$ & 0.10 & 0.25 & 0.50 & 0.10 & 0.25 & 0.50 & 0.10 & 0.25 & 0.50 \\
\hline
\end{tabular}
adhesion. The shaded areas identify the parameter space for good adhesion

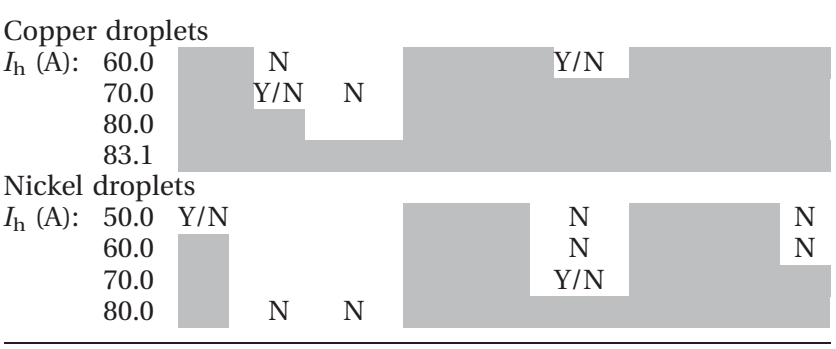

poor for thicker target, lower heating current $I_{\mathrm{h}}$ (and hence cooler droplet), and higher thermal diffusivity target material (see Table 1). The parameter spaces for which adhesion has been identified or is expected to be good is identified in Table 2 by shading.

The average cap height versus average base diameter of the adhering copper droplets, from the tests summarized in Table 2, is plotted in Fig. 5. Again a clear distinction can be seen between droplets with good adhesion, which tend to be wider and lower, and droplets with poor adhesion, which tend to be narrower and taller.

\subsection{High-speed video images}

An impact velocity of $0.70 \mathrm{~m} / \mathrm{s}$ was estimated from the high-speed video images. Images of oscillation after impact on a $0.5 \mathrm{~mm}$ copper plate of a copper droplet produced with an 83.1A heating pulse are presented in Fig. 6. These parameters give a droplet with good adhesion. The images are at the instants of the first four oscillation extrema after impact. The diameter of the droplet at the interface with the target is the same for all four images - i.e. the lowest layer of the droplet solidifies during the first spreading motion before the first minimum of height is reached and the droplet recoils. The solidified portion can be seen at the bottom of the droplet in the image labelled $5.1 \mathrm{~ms}$. The time from the initial contact of the droplet with the surface (not shown) to the minimum in height is $1.8 \mathrm{~ms}$. The period of the first oscillation (minimum height to minimum height) is $5.1 \mathrm{~ms}$. The final shape of the frozen droplet, having a rippled texture owing to the oscillations, is also shown. It took $20 \mathrm{~ms}$ from impact for the droplet to stop oscillating. The period of the oscillations decreases with time, as can be seen in Fig. 7. 


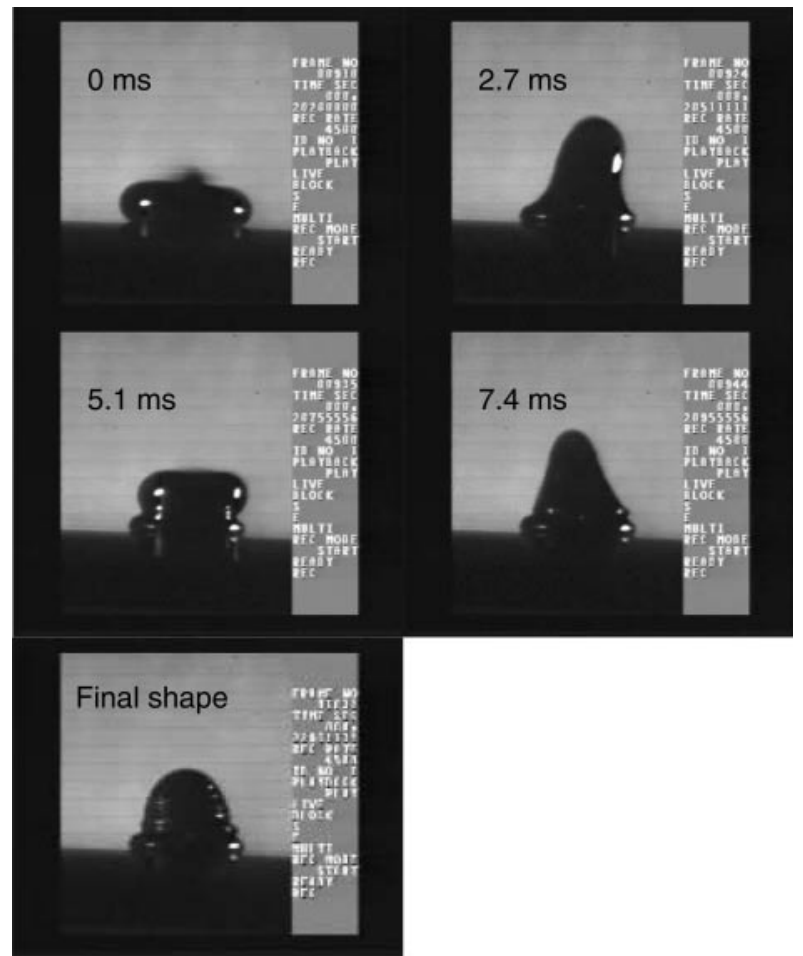

Fig. 6 High-speed video images of copper droplet oscillating on a $0.5 \mathrm{~mm}$ thickness copper plate after impact (83.1A heating current): 0 ms-first instant of maximum diameter after impact; $2.7 \mathrm{~ms}$-first instant of maximum height after impact; $5.1 \mathrm{~ms}-$ second instant of maximum diameter; $7.4 \mathrm{~ms}-$ second instant of maximum height. Also shown is the final solidified shape

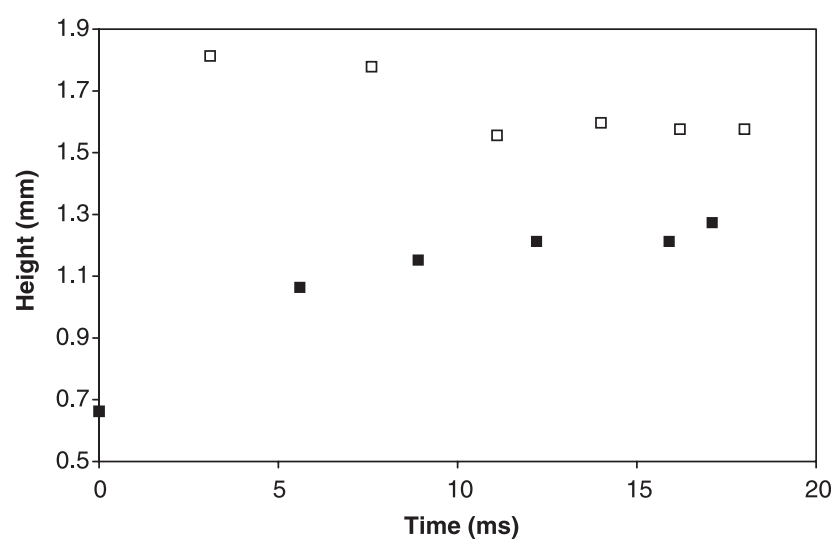

Fig. 7 Height variation with time after first instant of minimum height for droplet in Fig. 5 (filled squares - minima, hollow squares - maxima)

\subsection{Thermal model results}

The calculated thermal energies per unit mass at the surface of the workpieces for copper and nickel droplets on $0.1,0.25$, and $0.5 \mathrm{~mm}$ thick workpieces of copper, aluminium, and stainless steel at arc currents ranging from the minimum to give a droplet, through to the maximum that the machine could deliver, are shown in Figs 8 to 13. The curves are annotated with the experimental findings of droplet adhesion. The radii at which the curves cross the melting temperature and melting point specific energies for each droplet/ substrate combination are summarized in Table 3.

It can be seen that for copper droplets on aluminium and copper substrates and for nickel droplets on aluminium, copper, and stainless steel substrates, the droplet adhesion correlates with surface melting of the substrate over more than two thirds of the droplet contact area, i.e. there is melting over a radius of about $0.8 \mathrm{~mm}$ for a droplet of $1 \mathrm{~mm}$ radius. A slightly higher value of melting over the whole contact area for adhesion is seen for nickel droplets on an aluminium substrate. A much lower value of surface temperature rise is seen for adhesion of copper droplets on a stainless steel substrate.

\section{DISCUSSION}

\subsection{Droplet geometry and adhesion results}

The observation from Fig. 5 that droplets with larger diameter and smaller height have better adhesion is consistent with the results of Table 2 that hotter droplet/lower thermal diffusivity target/thinner target give the best adhesion. In the high-speed images it can be seen that the bottom layer of the droplet solidifies during the initial droplet spreading phase immediately after impact. Assuming freezing at the droplet/target interface during the initial droplet spreading phase for all the droplet/target parameters in the study, a hotter droplet on a lower thermal diffusivity or thinner target will spread further before freezing at the droplet/target interface. Adhesion can then be viewed as determined by competition between the delivery of thermal energy from the droplet to the target immediately underneath the droplet, and the removal of the energy from the interface region to the rest of the target. The combination of hotter droplet/lower thermal diffusivity target/thinner target gives the best chance of raising the temperature at the droplet/target interface high enough for re-melting to occur and for a weld to form.

In Fig. 4 the joint diameters for droplets with good adhesion vary in diameter by only \pm 5 per cent over the range of MIG pulse parameters, target thickness, and target materials studied. Since droplet oscillation does not appear to affect adhesion for the droplet temperatures and impact velocities produced by the droplet welding machine, a relatively simple thermal model to calculate the heat transfer 

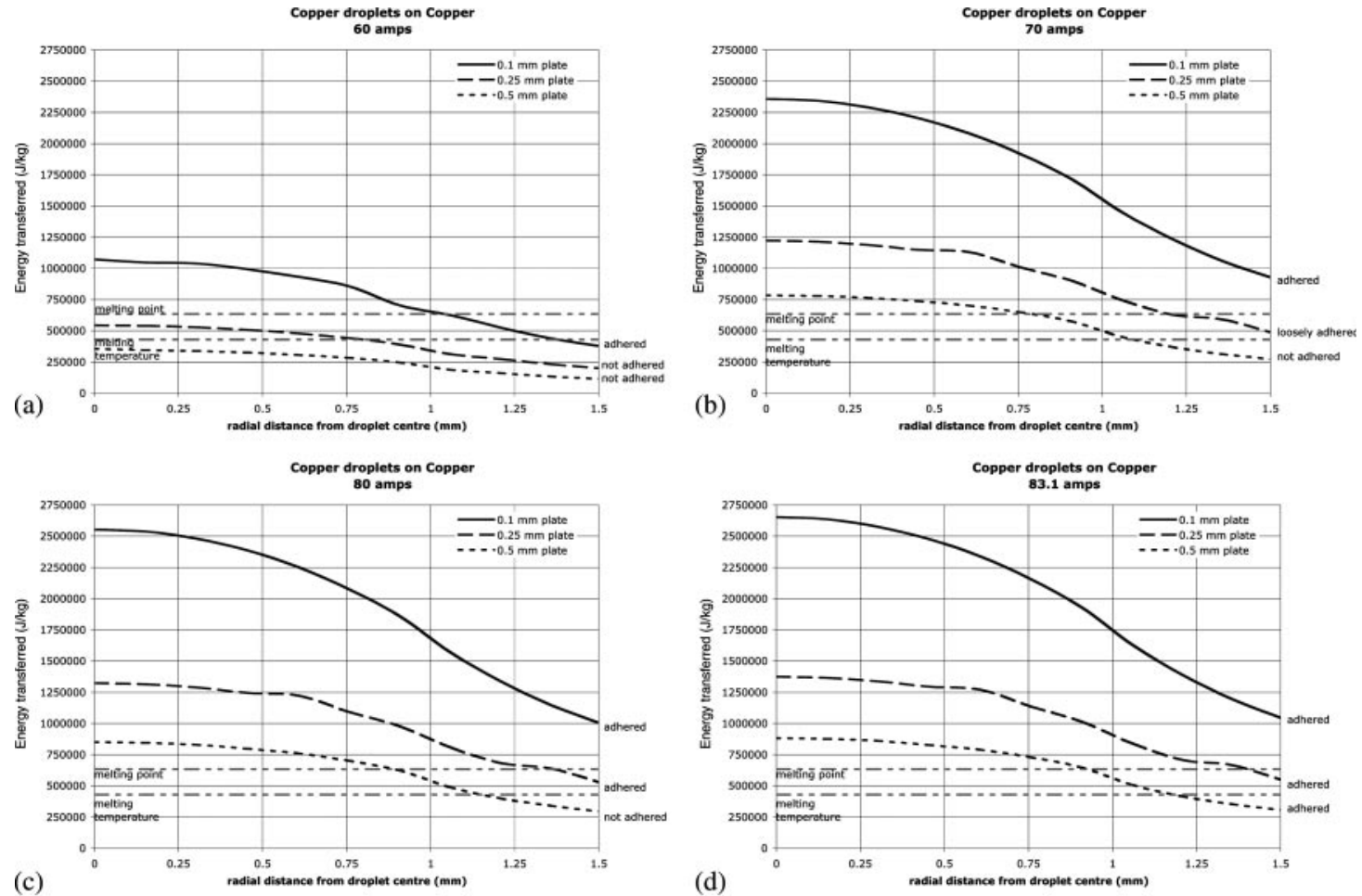

Fig. 8 Predicted thermal energy per unit mass distribution on workpiece surface of a copper droplet

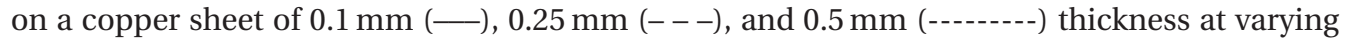
arc currents (a) $60 \mathrm{~A}$, (b) $70 \mathrm{~A}$, (c) $80 \mathrm{~A}$, and (d) maximum current $83.1 \mathrm{~A}$. Values calculated using a simple thermal model. Experimental adhesion results annotated
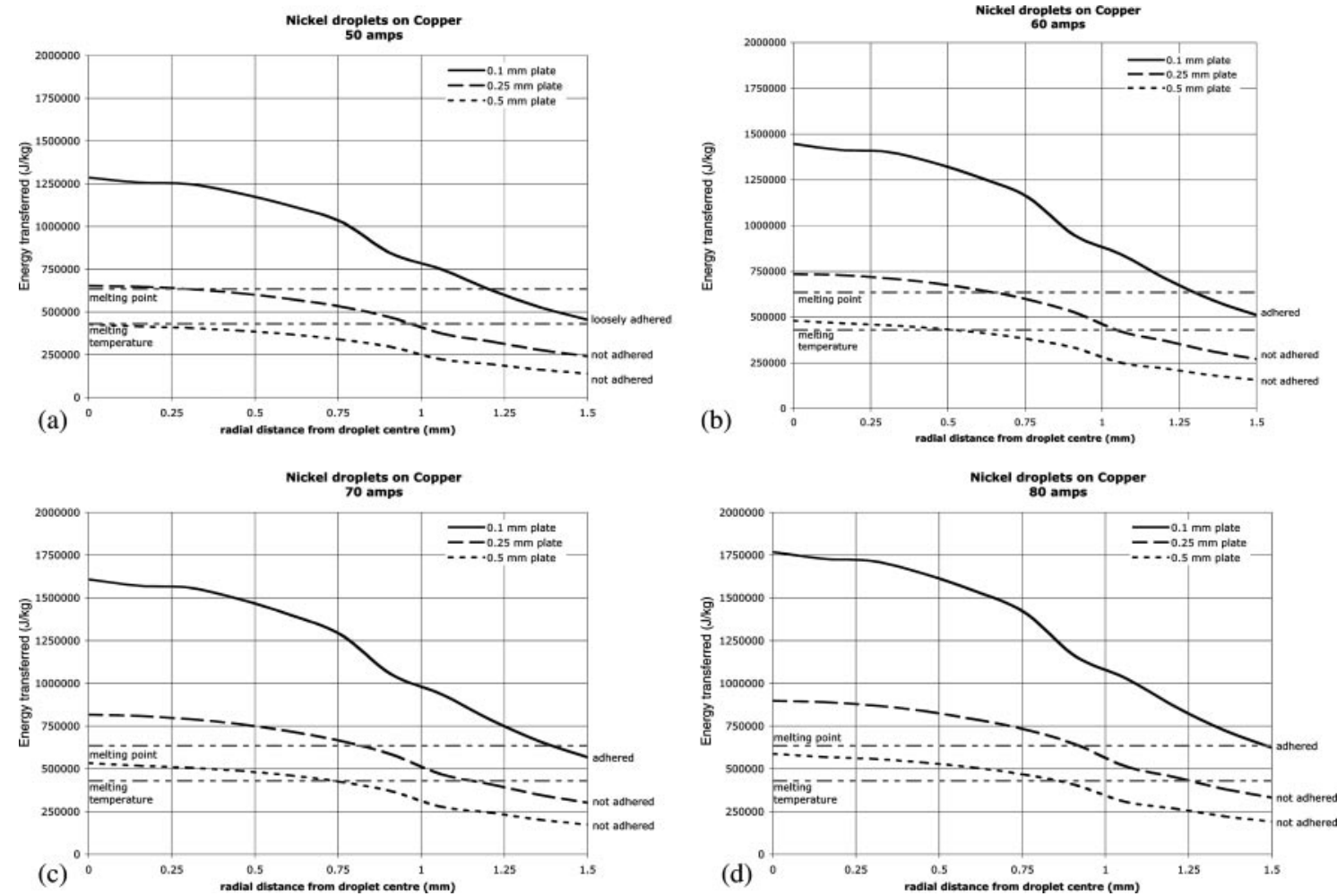

Fig. 9 Predicted thermal energy per unit mass distribution on workpiece surface of a nickel droplet on

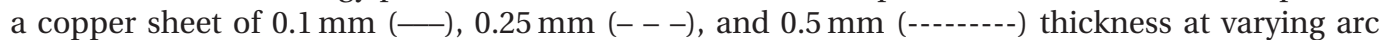
currents (a) $50 \mathrm{~A}$, (b) $60 \mathrm{~A}$, (c) $70 \mathrm{~A}$, and (d) $80 \mathrm{~A}$. Values calculated using a simple thermal model. Experimental adhesion results annotated 

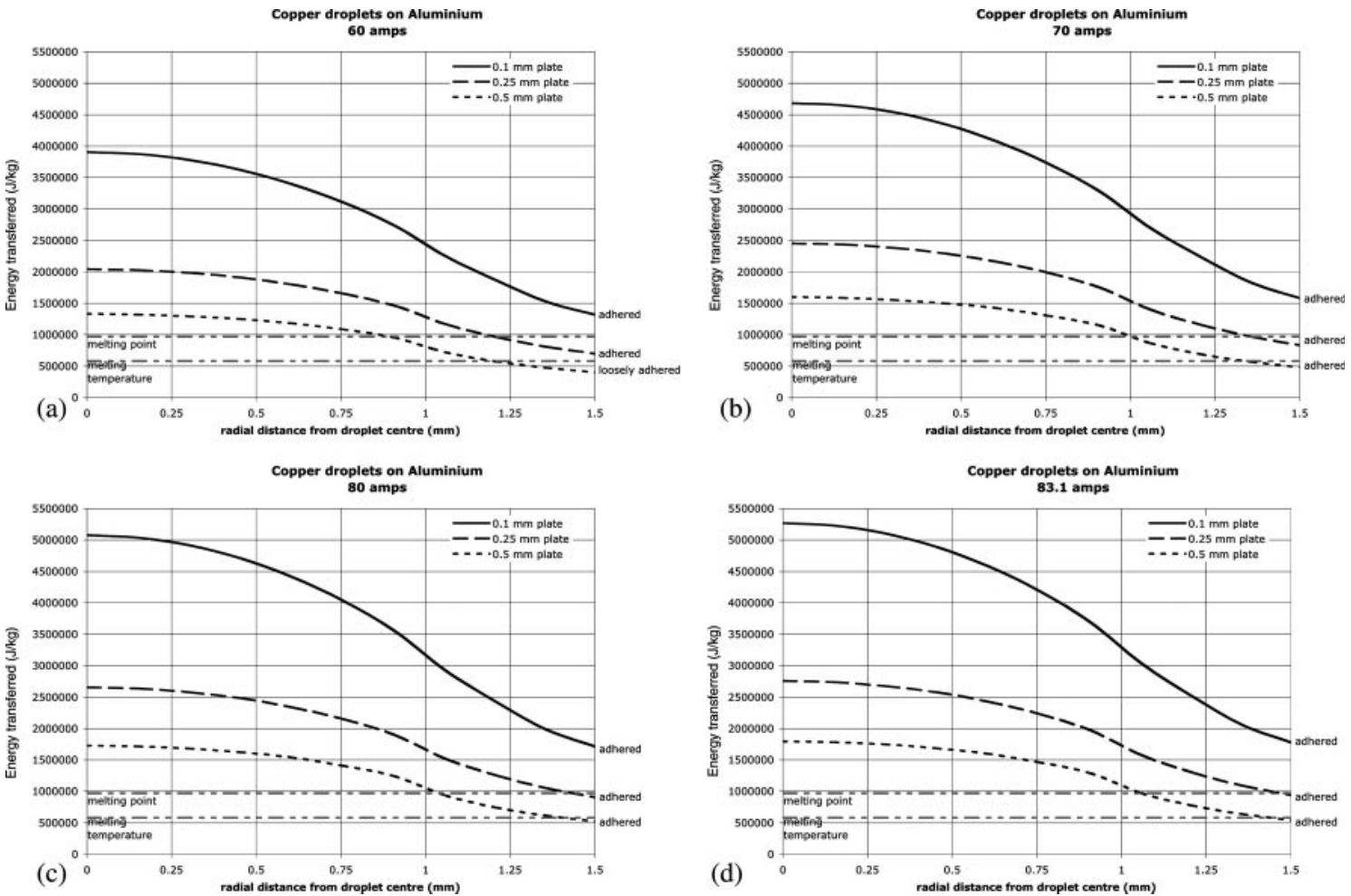

(c)

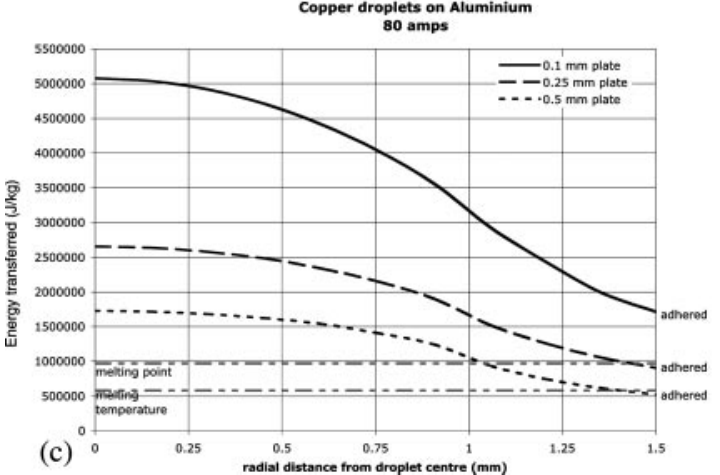

(d)

Fig. 10 Predicted thermal energy per unit mass distribution on workpiece surface of a copper droplet on an aluminium sheet of $0.1 \mathrm{~mm}(-), 0.25 \mathrm{~mm},(---)$, and $0.5 \mathrm{~mm}(-------)$ thickness at varying arc currents (a) $60 \mathrm{~A}$, (b) $70 \mathrm{~A}$, (c) $80 \mathrm{~A}$, and maximum current (d) $83.1 \mathrm{~A}$. Values calculated using a simple thermal model. Experimental adhesion results annotated

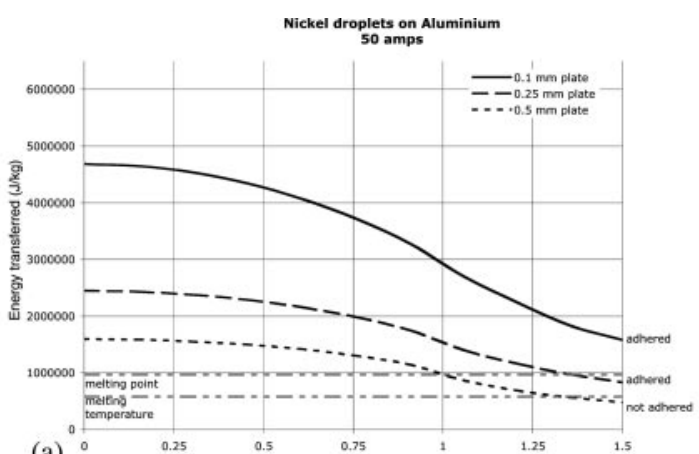

(a)
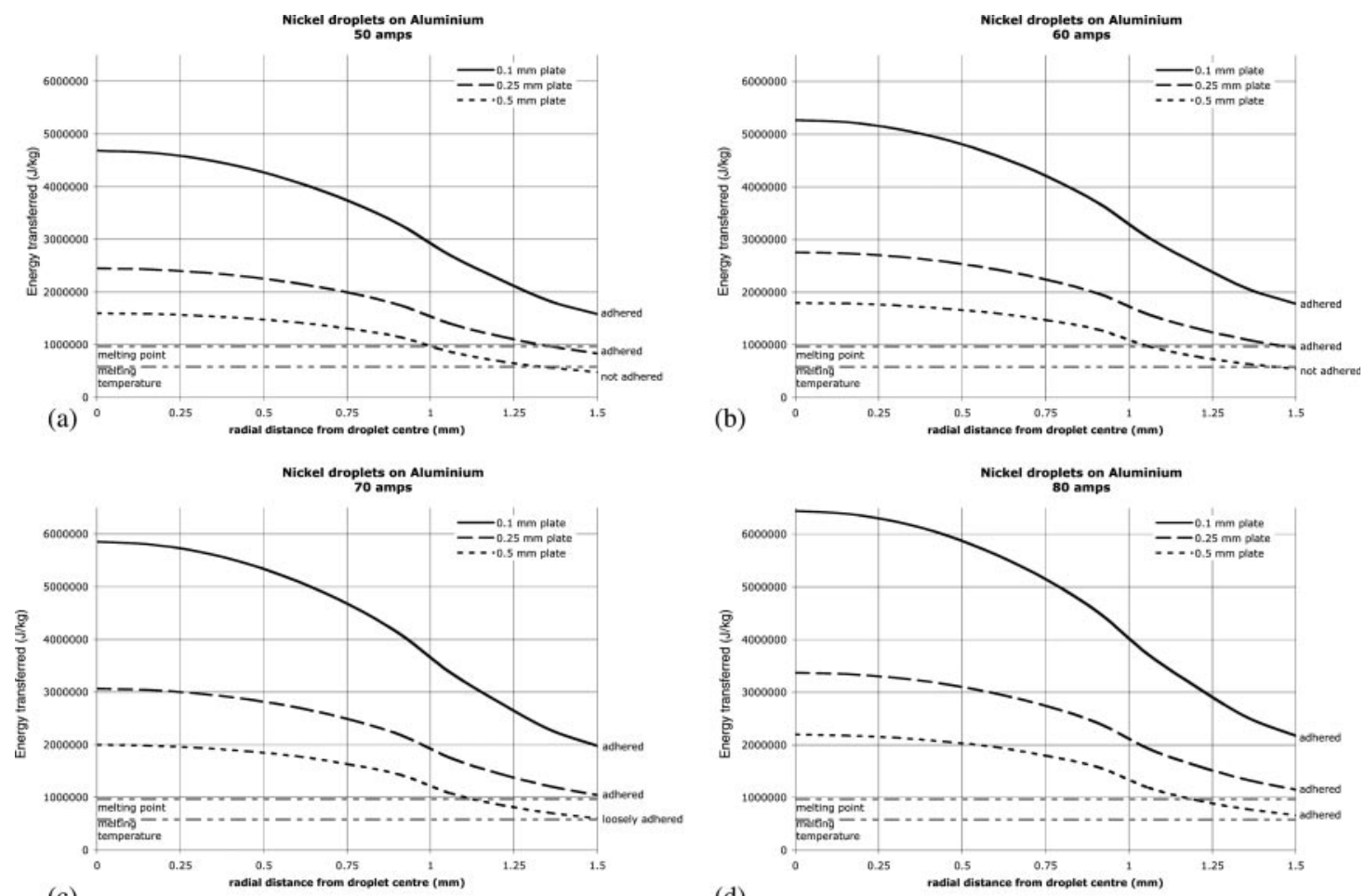

(c)

(d)

Fig. 11 Predicted thermal energy per unit mass distribution on workpiece surface of a nickel droplet

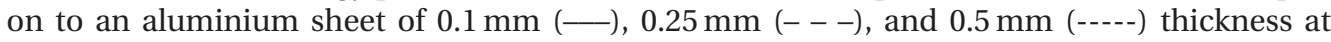
varying arc currents (a) $50 \mathrm{~A}$, (b) $60 \mathrm{~A}$, (c) $70 \mathrm{~A}$, and (d) $80 \mathrm{~A}$. Values calculated using a simple thermal model. Experimental adhesion results annotated 

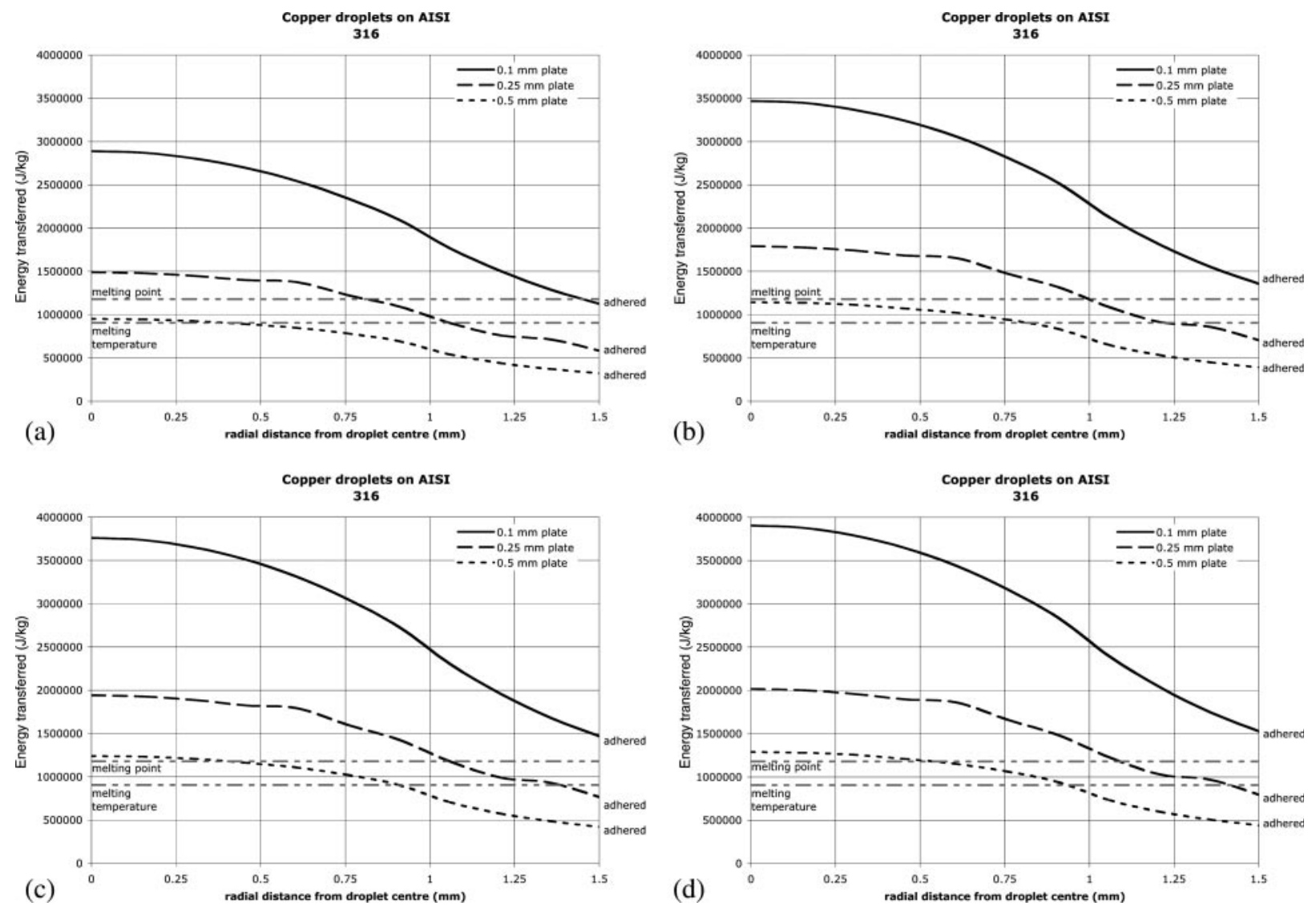

Fig. 12 Predicted thermal energy per unit mass distribution on workpiece surface of a copper

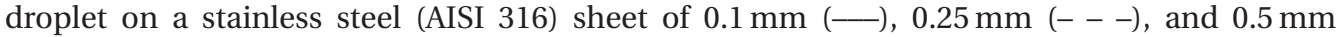
(---) thickness at varying arc currents (a) $60 \mathrm{~A}$, (b) $70 \mathrm{~A}$, (c) $80 \mathrm{~A}$ and maximum current (d) $83.1 \mathrm{~A}$. Values calculated using a simple thermal model. Experimental adhesion results annotated

from a droplet to a target material using the average solidified shape determined from characterization experiments should be enough for process set-up with the droplet welding machine. See, however, the discussion on re-melting depth below.

Comparison of the results in this work with the literature is complicated by the variety of materials and deposition conditions reported. Delplanque and Rangel [6] cover copper droplets deposited under similar conditions to this work $\left(2 \mathrm{~mm}^{3}\right.$ volume, $1 \mathrm{~m} / \mathrm{s}$ impact velocity). The solidified cap diameters estimated of 1.8 to $1.9 \mathrm{~mm}$ are similar to those in Fig. 5 for poor adhesion. However it is not clear that a spreading disk model such as that of Delplanque and Rangel describes the behaviour seen in the high-speed video images in Fig. 6, where mechanical energy continues to be dissipated long after the droplet base has frozen. This behaviour and the consequent rippled texture of the frozen droplet is reproduced by the computationally intensive simulations of Attinger and Poulikakos [13] for $\mathrm{SnPb}$ solder microdroplets (80 micron).
Attinger and Poulikakos infer that decoupling of fluid dynamics from heat transfer in theoretical models is precluded by the similar time scales of the fluid dynamics and substrate re-melting found in their simulations. This conclusion is reinforced by the finding that an increase in impact velocity increases the volume of substrate re-melting, at least for the case treated. Rangel and Bian [10], using a disk-spreading model capable of including the effect of re-melting, on the other hand find that the maximum depth of substrate re-melting is larger for lower velocity for $1 \mathrm{~mm}$ aluminium droplets impacting at $1 \mathrm{~m} / \mathrm{s}$ to $10 \mathrm{~m} / \mathrm{s}$. For the droplet welding machine the droplet detachment velocity is determined by the pinch pulse parameters. Since these were kept constant in the experiments there is not expected to be any significant effect of impact velocity on adhesion represented in the results. In the context of process set-up it seems likely that any influence of impact velocity on adhesion would be greatest in the marginal poor adhesion cases. 

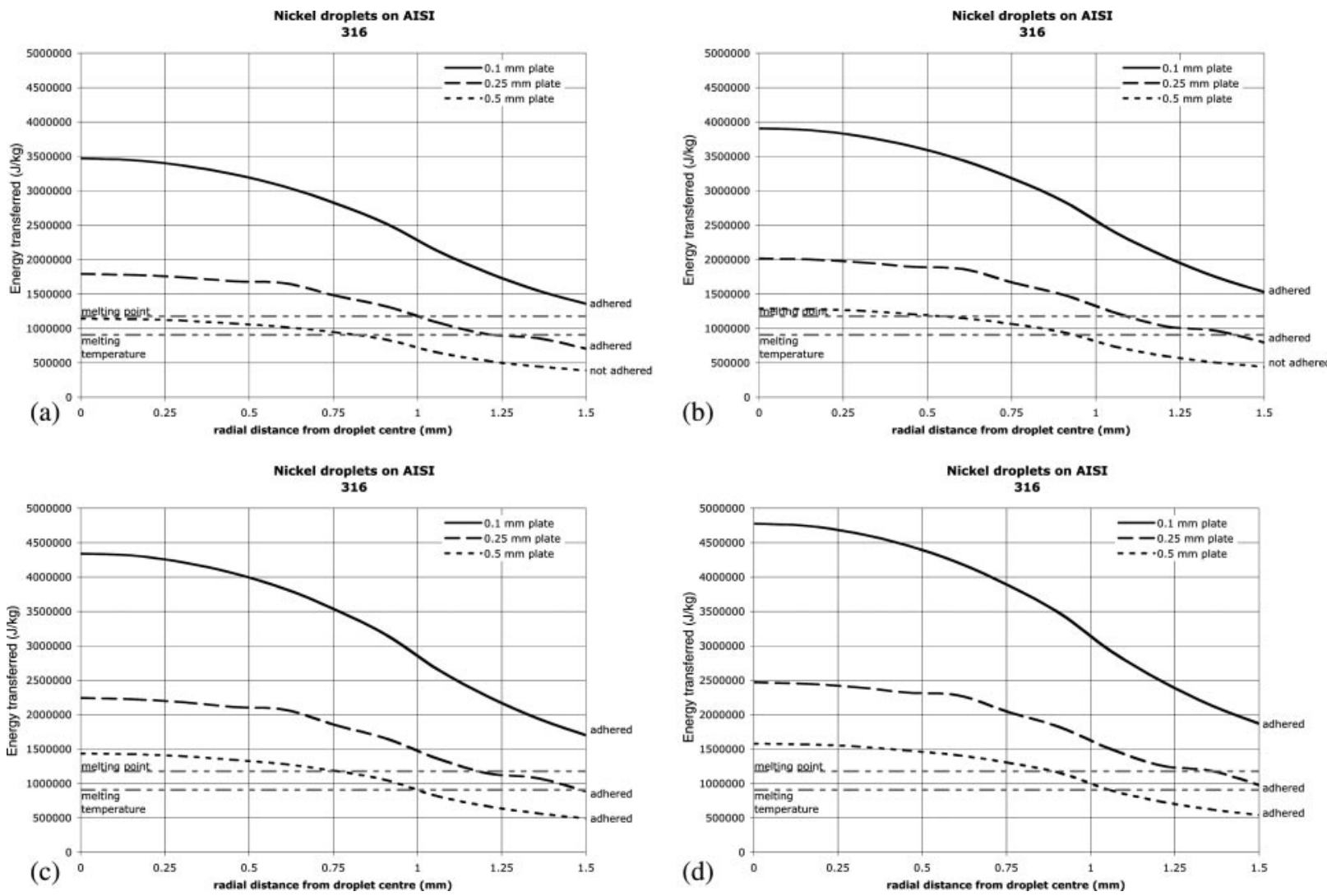

Fig. 13 Predicted thermal energy per unit mass distribution on workpiece surface of a nickel droplet on a stainless steel (AISI 316) sheet of $0.1 \mathrm{~mm}(-), 0.25 \mathrm{~mm}(---)$, and $0.5 \mathrm{~mm}(----)$ ) thickness at varying arc currents (a) $50 \mathrm{~A}$, (b) $60 \mathrm{~A}$, (c) $70 \mathrm{~A}$, and (d) $80 \mathrm{~A}$. Values calculated using a simple thermal model. Experimental adhesion results annotated

\subsection{Thermal model adhesion results}

The simple mathematical thermal model generally gives a good indication of whether or not to expect droplet adhesion. However, it does not explain the observation of relatively lowtemperature adhesion of copper droplets to a stainless steel substrate. That no melting in the substrate occurs is supported by metallographic crosssections as shown in Fig. 14. A cross-section of a copper droplet on a copper target exhibiting continuous microstructure at the droplet-target interface is shown for comparison. The consistency of the nickel droplet on stainless steel substrate predictions with the other predictions and the experimental results gives confidence in the ability of the simple thermal model to cope with the low conductivity stainless steel. Some other factor must therefore be sought to account for the copper/stainless steel results.

Of the three substrates chosen to work with, stainless steel has the largest melting range. Some phases may start to melt at temperatures as low as $1300^{\circ} \mathrm{C}$. Compared with a melting temperature of approximately $1500{ }^{\circ} \mathrm{C}$, this would require significantly less energy transfer. However, this effect should also be seen with the nickel droplets on the stainless steel substrate and it is not.

Iron, making up 75 per cent of the stainless steel, and copper are almost insoluble, [20], so rapid diffusion to the iron based matrix is unlikely; the same is true of chromium (18 per cent). While nickel (8 per cent) and copper are completely soluble, it seems unlikely to be the mechanism for the lowtemperature adhesion, as the nickel is dispersed within the iron matrix.

A remaining option is a chemical reaction. While copper oxide and chromium oxide (found at the surface of a stainless steel) are catalysts for many industrial organic chemistry reactions, this is a mixture of the two oxides and not a compound. Spinels, crystalline oxides with more than one metallic component (often magnesium and aluminium oxide), are also an unlikely source of the nonmelting adhesion. A definitive identification of the adhesion mechanism for the copper/stainless steel combination is outside the scope of the current paper. 
Table 3 Predicted positions of the point of reaching the melting temperature and melting the substrate surface for different droplet/substrate combinations for a $1.01 \mathrm{~mm}$ droplet diameter. The point of adhesion or not was determined by the experimental results. Adhesion is generally seen when the melting temperature is reached over at least $0.8 \mathrm{~mm}$ (2/3rds of the contact area)

\begin{tabular}{|c|c|c|c|c|c|}
\hline \multirow[b]{2}{*}{ Droplet } & \multirow[b]{2}{*}{ Substrate } & \multicolumn{2}{|c|}{ Adhered } & \multicolumn{2}{|c|}{ Not adhered } \\
\hline & & $\begin{array}{l}\text { Minimum } \\
\text { radius to melting } \\
\text { temperature (mm) }\end{array}$ & $\begin{array}{l}\text { Minimum radius } \\
\text { to melting } \\
\text { point }(\mathrm{mm})\end{array}$ & $\begin{array}{l}\text { Maximum radius } \\
\text { to melting } \\
\text { temperature }(\mathrm{mm})\end{array}$ & $\begin{array}{l}\text { Maximum radius } \\
\text { to melting } \\
\text { point }(\mathrm{mm})\end{array}$ \\
\hline Copper & Copper & 1.2 & 0.9 & 1.2 & 0.8 \\
\hline Copper & Aluminium & 1.2 & 0.85 & - & - \\
\hline Copper & Stainless steel & 0.5 & Not reached & - & - \\
\hline Nickel & Copper & 1.5 & 1.2 & 1.25 & 0.7 \\
\hline Nickel & Aluminium & 1.5 & 1.15 & 1.3 & 1.0 \\
\hline Nickel & Stainless steel & 1 & 0.8 & 0.9 & 0.5 \\
\hline
\end{tabular}
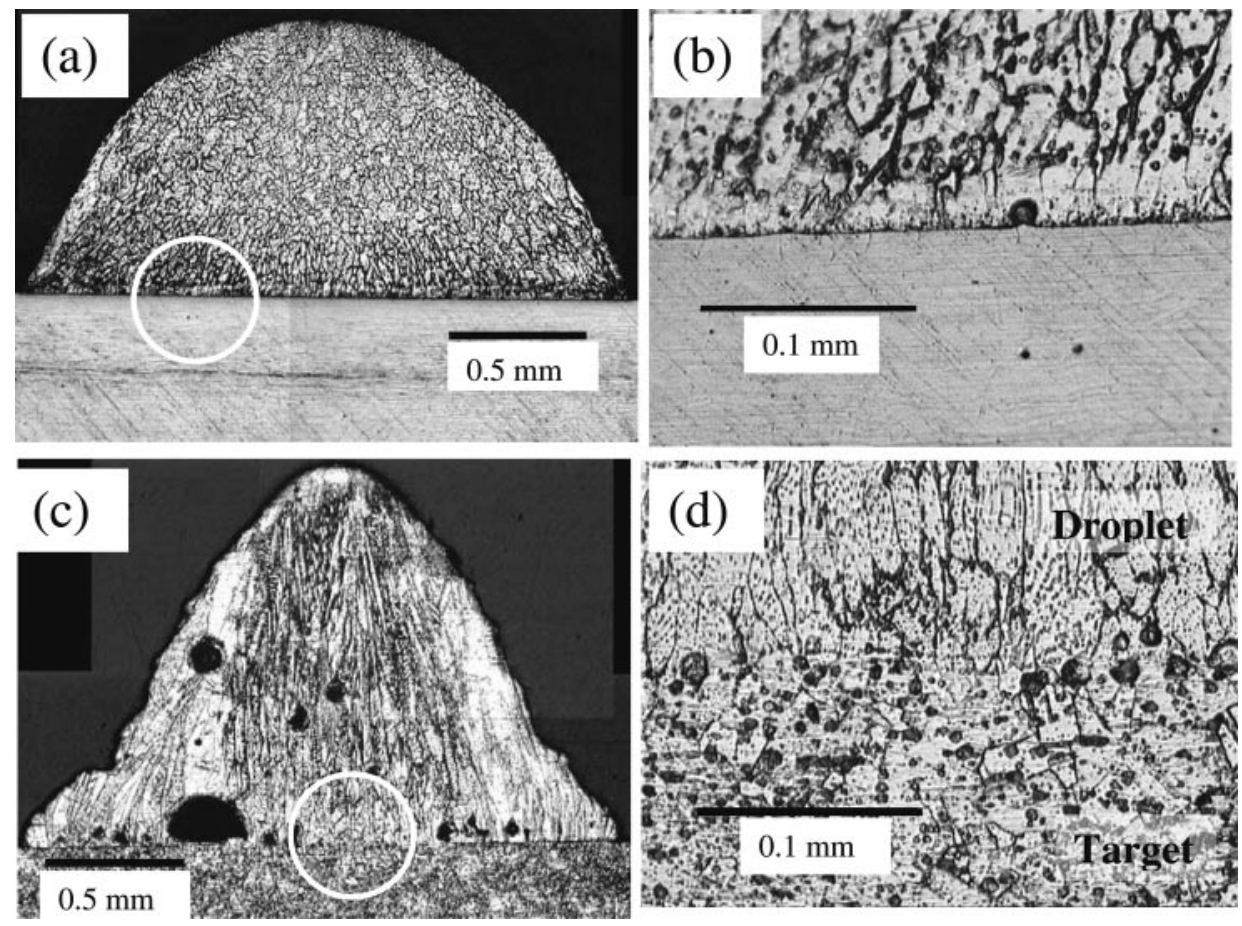

Fig. 14 Metallographic cross-sections of: (a) copper droplet $I_{\mathrm{h}} 60 \mathrm{~A}$ on $0.5 \mathrm{~mm}$ stainless steel target, (b) detail from circled area, (c) copper droplet $I_{\mathrm{h}} 83.1 \mathrm{~A}$ on $0.5 \mathrm{~mm}$ copper target, (d) detail from circled area

\section{CONCLUSIONS}

An experimental investigation into factors affecting adhesion of lead-free high-temperature electrical joints produced by a droplet welding process has been carried out. The motivation for the work was the need to provide the basis of a simple method of process set-up for new products. The topic of impact of molten metal droplets on a surface has been much reported in the literature. In this context the contribution of the current study is to look at the adhesion of the solidified droplets to the target, and the effect of finite substrate thickness.
Adhesion of copper and nickel droplets of varying temperature impacting at $0.7 \mathrm{~m} / \mathrm{s}$ on copper, aluminium, and stainless steel target plates of varying thickness was determined. Regions in the parameter space producing good adhesion and poor adhesion were found to exist. Good adhesion regions were characterized by combinations of hotter droplet, thinner target, and lower thermal diffusivity target as might be expected. High-speed images of droplet impact reveal the base of the droplet freezes during the initial expansion stage following impact. The remaining liquid portion of the droplet above the frozen base oscillates until the whole droplet 
freezes. Since the variation in good joint diameter is small and the oscillation of the droplets do not appear to affect adhesion, it is suggested that a relatively simple thermal model could identify the parameter space for good adhesion for rapid process set-up.

Such a model, based on an analytic solution to the heat conduction problem for a circular heat source, has been shown to be reliable at predicting adhesion between the droplet and target. It was found that the energy flux from the droplet to the target must be sufficient to cause melting at the interface across at least two thirds of the droplet contact area.

Some theoretical studies in the literature find that droplet impact velocity has an effect on target remelting depth, which could be expected to affect adhesion strength. The effect of impact velocity was not determined in this work and so could be the subject of a further study. However, it might be expected that any effect of variation in impact velocity would be greatest in cases of marginal poor adhesion.

\section{ACKNOWLEDGEMENTS}

The authors would like to acknowledge the financial support of the European Commission for project DropletWeld under contract number G1RD-CT 2000-00209 and the support of our project partners, in particular Philips CFT and Macgregor Welding Systems Ltd.

\section{REFERENCES}

1 Directive 2002/95/EC of the European Parliament and of the Council of 27 January 2003 on the restriction of the use of certain hazardous substances in electrical and electronic equipment. Official J. Eur. Union, 2003, L37, 19-23.

2 European Community Fifth Framework Programme Proposal Number GRD1-1999-10369, 1999.

3 Waldvogel, J. M. and Poulikakos, D. Solidification phenomena in picoliter size solder droplet deposition on a composite substrate. Int. J. Heat Mass Transfer, 1997, 40, 295-309.

4 Madejski, J. Solidification of droplets on a cold surface. Int. J. Heat Mass Transfer, 1976, 19, 1009-1013.

5 Carslaw, H. S. and Jaeger, J. C. Conduction of heat in solids, 2nd edition, 1959 (Oxford University Press, Oxford).

6 Delplanque, J. P. and Rangel, R. H. An improved model for droplet solidification on a flat surface. J. Mater. Sci., 1997, 32, 1519-1530.

7 San Marchi, C., Liu, H., Lavernia, E. J., Rangel, R. H., Sickinger, A., and Muehlberger, E. Numerical-analysis of the deformation and solidification of a single droplet impinging onto a flat substrate. J. Mater. Sci., 1993, 28, 3313-3321.

8 Kim, H. Y. and Chun, J. H. The recoiling of liquid droplets upon collision with solid surfaces. Physics Fluids, 2001, 13, 643-659.
9 Yang, Y. S., Kim, H. Y., and Chun, J. H. Spreading and solidification of a molten microdrop in the solder jet bumping process. IEEE Trans Components Packaging Technol., 2003, 26, 215-221.

10 Rangel, R. H. and Bian, X. Metal-droplet deposition model including liquid deformation and substrate remelting. Int. J. Heat Mass Transfer, 1997, 40, 2549-2564.

11 Schmaltz, K. S., Zarzalejo, L. J., and Amon, C. H. Molten droplet solidification and substrate remelting in microcasting - part Ii: parametric study and effect of dissimilar materials. Heat Mass Transfer, 1999, 35, $17-23$.

12 Zarzalejo, L. J., Schmaltz, K. S., and Amon, C. H. Molten droplet solidification and substrate remelting in microcasting - part I: numerical modeling and experimental verification. Heat Mass Transfer, 1999, 34, 477-485.

13 Attinger, D. and Poulikakos, D. Melting and resolidification of a substrate caused by molten microdroplet impact. J. Heat Transfer Trans ASME, 2001, 123, 1110-1122.

14 Liu, H. M., Lavernia, E. J., and Rangel, R. H. Numerical-simulation of substrate impact and freezing of droplets in plasma spray processes. J. Phys. D-Appl. Phys., 1993, 26, 1900-1908.

15 Liu, H., Lavernia, E. J., and Rangel, R. H. Modeling of molten droplet impingement on a nonflat surface. Acta Metallurgica Et Materialia, 1995, 43, 2053-2072.

16 Pasandideh-Fard, M., Chandra, S., and Mostaghimi, J. A three-dimensional model of droplet impact and solidification. Int. J. Heat Mass Transfer, 2002, 45, 2229-2242.

17 Buelens, J. C. and Waszink, J. H. Wire heating in the droplet deposition process. Philips CFT Internal Report CTR 543-92-0056, 1992.

18 Kiyohara, M., Yamamoto, H., and Harada, S. Melting characteristics of a wire electroded in the MIG-welding of aluminium. Proceedings of the International Conference on Arc physics and weld pool behaviour, London, 1979, pp. 165-175.

19 Waszink, J. H. and Van den Heuvel, G. J. P. M. Heat generation and heat flow in the filler metal in GMA welding. Welding J. Res Supplement, 1982, 269-282.

20 Brandes, E. A. and Brook, G. B. (editors) Smithells metals reference book, 7th edition, 1992 (ButterworthHeinemann, Oxford).

\section{APPENDIX}

\section{Notation}

$E_{\mathrm{d}} \quad$ thermal energy per droplet

$I_{\mathrm{h}} \quad$ heating pulse current

$I_{\mathrm{p}} \quad$ pinch pulse current

$L_{\mathrm{w}} \quad$ length of wire delivered per droplet

$Q$ charge passed during droplet generation pulse

$t_{\mathrm{h}} \quad$ duration of heating pulse

$t_{\mathrm{p}} \quad$ duration of pinch pulse

$V_{\mathrm{w}}$ proportionality constant between $Q$ and $E_{\mathrm{d}}$ 